\title{
Assessing the impacts of Light Rail Transit on urban land in Manila
}

\author{
Javier F. Pacheco-Raguz \\ Planning Division, TransLink ${ }^{\text {a }}$
}

\begin{abstract}
This paper presents an assessment of impacts of Light Rail Transit Line 1 (LRT1) in terms of accessibility and distance as they relate to variables such as land values, land uses, and population densities in Manila, Philippines. Using correlations and regressions, these variables are analyzed against an accessibility index and network distances obtained from a model built within a Geographic Information System (GIS). Land values, land uses, and population densities are influenced in a limited, though consistent, way by the accessibility provided by LRT1 and the distance to it. The analysis of impacts after the construction of LRT1 found that accessibility and distance were only consistent influences for residential land values, with marginal results for the rest of the variables. These results, when contrasted with the urban configuration of Manila and the studies reviewed, show that the limited impacts may be a consequence of good accessibility before LRT1 and the lack of complementary planning and policies for taking advantage of its influence.
\end{abstract}

Keywords: LRT; Light Rail Transit; transport; land value; land use; population; network distance; accessibility.

\section{Introduction}

It is widely recognized that transport and urban land development are closely related. The spatial distribution of human activities such as living or working creates demand for the transport of people and goods. However, the converse impacts of the transport side are less understood. Changes in accessibility are likely to influence the relative attractiveness of a location, potentially inducing shifts in land values, uses, or densities. These changes are a result of the relationship between transport, land, and human activities (housing, employment, industry, etc.), a tri-partite interaction that generates travel demand and the requirements for transport infrastructure. Good management of urban growth and densities, as well as adjustments in land use, ease the flow of socio-economic resources. Part of this management involves adding new infrastructure-housing, services, or transport-producing diverse impacts on urban land; the complexity of these impacts makes them difficult to assess.

Mass transport systems generate benefits ranging from a reduction of pollution to the orderliness of flows, shorter travel/dwell times, and a faster, more reliable service, handling peak flows of up to 60000 passengers/direction/hour. The provision of capacity for future growth is also essential for choosing such technologies (Pushkarev et al. 1982), as they are capital-intensive

apacheco@alumni.itc.nl 
with a long gestation period. In most cases, mass transport is the only reasonable alternative for a growing demand, requiring innovative funding as it ranges from tens to hundreds of millions of dollars per kilometer (Japan International Cooperation Agency 1999; Wright and Hook 2007). One of the most common is the LRT, with lower capacity than the heavier systems, though more flexible and less expensive.

A study by the Institute for Development and Transport Policy in the United States (Wright and Hook 2007) identified some of the most important factors influencing the selection of a transport system, grouped in categories such as cost, planning and management, design, performance, and impacts. The last of these is the topic of this study and includes economic, social, and environmental impacts as well as direct influence over urban areas. Some of the impacts observed are fostering/reduction of population density growth, change in operational patterns of bus transport systems, and enhancement/depression of areas within the city (possibly including economic revenues by changes in land uses and/or land values due to an improved accessibility). On the negative side, visual impacts and noise are the most common considerations. As a type of mass transport, LRT unavoidably affects urban land uses and activities, causing a variety of negative or positive impacts.

\section{Reviewing the transport and urban land relationship}

Planners have dedicated much effort to explaining the hidden connections between transport and land use. Figure 1 summarizes the relationship, showing the basic variables affected (positively or negatively) by the relationship. From the transport side, the first is accessibility, defined as the ease with which activities may be reached from a given location by means of a particular transport system (Morris et al. 1979). Another is proximity, based on the location of transport infrastructure in urban areas. Proximity is measured in distance, whether linear (also called Euclidean distance) or network-based (calculated using the road/path links). Changes in both variables (as well as in mobility) affect land uses and these also influence transport by generating more demand, altering transport networks, shifting modes, and generating congestion. Previous studies have demonstrated the importance of accessibility and proximity (among other factors) in urban areas, through their impacts on variables related to production, housing, employment, and services in urban areas. Some studies are reviewed in this section and attention is given to the location of the studies as well as the policy framework applied.

\subsection{Accessibility}

As accessibility increases, mobility becomes less costly—in time or money—and transport costs decline. Giuliano (1995) affirms that mass transport improves accessibility to areas within the transport corridor and increases their relative advantage compared to non-served areas. Hence, all else being equal, activities should shift towards stations along the corridor with increased land values. However, the importance of the integration of rail and buses cannot be neglected. Thanks to the current transport modes, the incidence of newly added accessibility is extended to an area wider than the rail corridor. Giuliano explains that modifying a single link on the transport network produces an overall impedance change (expressed in travel time) across the entire network, as the accessibility provided by existing transport is independent of that generated by new modes. It is undeniable that some bus routes may appear or change their itineraries 


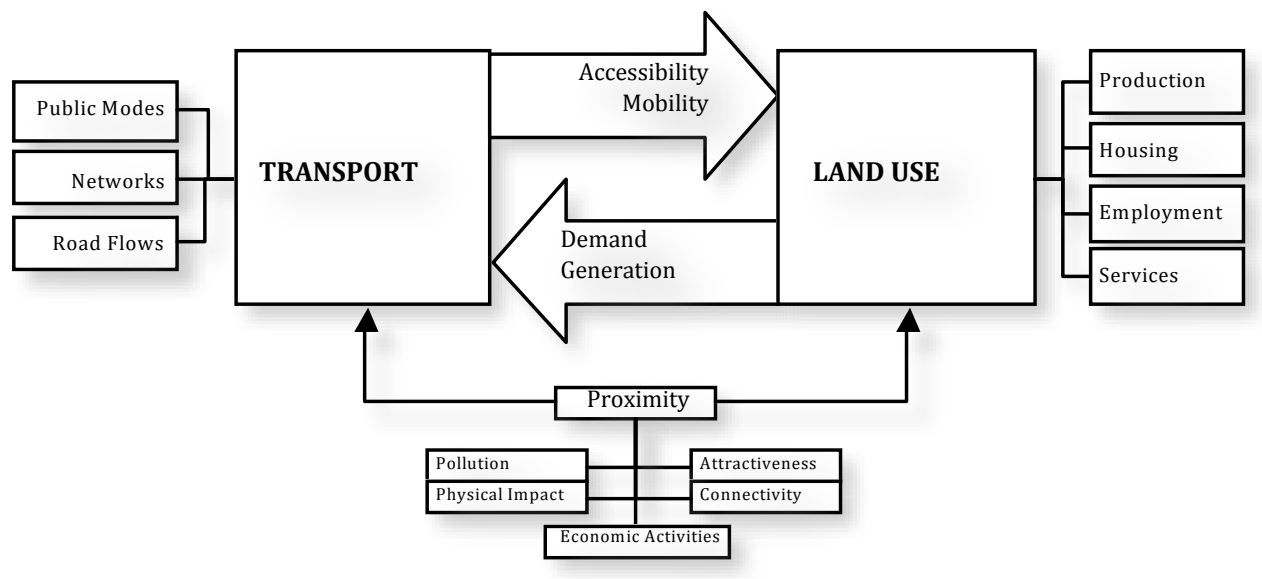

Figure 1: Schema of transport/land use interaction and some of the variables involved.

once a major transport mode is introduced. Indeed, such changes may lead to new land use patterns and should be considered, even they are not a direct effect of mass transport.

Geurs and Ritsema (2001) reviewed studies examining the effect of accessibility on travel behavior and land use. They pointed to a weak correlation between accessibility indexes and housing land values in a study of 43 Dutch regions. Similarly, Landis et al. (1994), studying five railway corridors, found that residential property values rise near the rail lines. Moreover, Bae et al. (2003) studied the impacts of Seoul's Subway Line 5 on land values by means of a hedonic price model and found that distance from the line had statistically significant effects on residential prices only prior to the line's opening. This is consistent with the anticipatory effect observed in other studies, and indicates that land values may be determined by many factors, including those unrelated to mass transport.

Among the most cited studies, Cervero and Landis (1997) analyzed the influence of San Francisco's Bay Area Rapid Transit (BART) on urban areas, including land uses. Although the study found correlations between BART's induced development and land use growth, it also pointed to factors such as zoning incentives, local citizen backing, and a buoyant economy. Cervero and Landis affirmed that, in the absence of these factors, BART would have had little influence on the location and form of growth. Moreover, Wegener and Fürst (1999) concluded that in general, the relationship between accessibility and land use tends to be weak, an idea supported by Hall and Marshall (2002) who challenged the conventional assumption of transport influencing urban land by affirming that effects may only manifest where accessibility is low. Regarding this challenge, Cervero and Wu (1998) noted that factors other than accessibility increasingly influence metropolitan location decisions. In the BART study, they came to the "inevitable conclusion" that there is only a tenuous link between urban-rail transport and land development.

Research by the Royal Institute of Chartered Surveyors (RICS Policy Unit 2002) in the UK showed that some impacts even capitalize land values due to travel-time monetary savings. Bichsel (1999) asserted that the price of land with greater accessibility tends to decrease, contradicting some theories of transport accessibility that suggest improvement might only lead to 
an increase in land's attractiveness to, e.g. commercial projects, thus generating greater values. In any case, this result depends on the urban configuration, the potential of land based on its capacity, and the complementary policies applied.

\subsection{Proximity}

Distance (linear or network-measured) is other main variable when analyzing the transport influence on urban areas. As seen in Figure 1, the variable works in two ways: the presence of transport infrastructure affects land uses by causing pollution or visual impact; land uses (e.g. commerce or housing) affect transport by attracting travel flows. As opposed to accessibility, the effects of proximity to transport infrastructure have been examined only sparingly as noted in research by the Transit Cooperative Research Program (2002). This thorough review of literature on impacts near rail stations in several cities in the United States pointed out that proximity to stations raises property values, all else being equal, although to varying degrees. The conclusions of all the studies reviewed (see the full study for a detailed list) showed mixed results, for both residential and commercial land values. The review also included a separation of impacts by heavy and light transport systems. Gardner et al. (1990) showed that LRT might also be considered as a potential catalyst for other urban development though detailed research by Hall and Hass-Klau (1985) and Simpson (1990) suggested that these benefits are often exaggerated.

A recent study by Debrezion et al. (2007) also reported positive increments in commercial property values closer to railway stations in the Netherlands. They also found that railway stations are expected to have a higher positive effect on commercial properties compared to residential properties for relatively short distances from the stations. In addition, the study tested a methodology for understanding the variety of results of studies in transport impacts on property values.

\subsection{The importance of location and policy context}

An important analysis of mass transport impacts by Fouracre et al. (1990) included a thorough investigation of changes in transport indicators such as time savings, passenger shifts, and differences in operational patterns. This research defined development guidelines and included suggestions for developing an integrated urban and transport planning process. However, Fouracre et al. pointed out that only limited research on the performance and impact of mass transport projects had been undertaken in developing countries. Together with the already quoted document by the Institute for Development and Transport Policy, Fouracre et al. at the Transport and Road Research Laboratory in the United Kingdom made of the few studies in emerging economies. The research comprised studies of 21 cities worldwide (Manila included) and concluded that the scale of transport-induced development is small. This result concurs with research by Walmsley and Perret (1992), who pointed out that such development is generally the result of positive government intervention.

It is evident that there is a lack of a comparable number of studies focusing on cities in emerging economies. The impacts of mass transport systems assessed in most of the studies reviewed may not be transferable to these without a clear methodology that is beyond the scope of the present study. However, the analysis of impacts may show a similar pattern regardless of locational factors, in terms of a pure correlation between transport and land use variables. 
Regardless of location, studies about the relationship of accessibility induced by transport improvement and its effect on urban areas have shown that the extent of such impacts is limited. This is to be expected, as urban areas are also influenced by other factors, such as land use development, policies, or general economic factors. Where impacts have been considered significant, both negative and positive impacts have been identified. The intervention of authorities or private stakeholders managing the development produced by changes in the transportation system - whether by policies, incentives, or direct investment-is considered decisive. Transport Oriented Development (TOD) is one of the latest concepts related to taking advantage of these influences, considering policy intervention and private participation (Lefaver 1997; Transit Cooperative Research Program 2002). To the degree that TOD and its joint-development variant confer travel-time savings and enhance accessibility, the theory holds that these privatesector benefits will be capitalized into land values and market rents. Cervero (1984); Emerson (1990); Knight (1980) also identified the provision of public infrastructure and financial incentives as important to attract and support development around stations. Without a positive intervention by authorities or stakeholders, Walmsley and Perret (1992) and Dabinett et al. (1999) claimed that transport investments are often necessary but not sufficient to generate development. Well-developed transport facilities alone cannot explain the agglomeration of economic activities due to the incapacity of transport facilities to provide users a utility per se (Bichsel 1999). Moreover, Hall and Marshall (2002) noted two particularly important contextual items regarding transport investment on development: first, infrastructure investment has led land use development in buoyant economies; second, the regulatory context (e.g. planning controls) implies that transport-led development tends to flourish where policies favor TOD. In this respect, the place where the analysis of transport and land use is done use should point toward more significant impacts in cities of the developed world. However, Gakenheimer (1999) argued that there are stronger linkages between land use and transport in the developing world, an idea that other studies do not support.

According to Dabinett et al. (1999), mass transport can have a strong influence on the location, intensity, and timing of new development, especially when supported by positive incentives and coordinated land use/transport planning. Greeneberg (1988) and Pill (1988) demonstrated the importance of the planning context. They showed that authority-driven zoning bonuses for new urban land developments around Toronto subway stations proved to be the most significant impacts over urban areas where stringent land use controls directed the changes (Giuliano 1995).

\subsection{Framework of the study}

Most of the research assessing transport impacts on urban land use show that the most frequently recurring variables are accessibility and distance. These variables were used together by Rietveld and Nijkamp (2000) to demonstrate that a higher level of access and closer proximity to transport may increase property values. The basic premise in this study is that changes in transport infrastructure will have an impact on the relative attractiveness of certain areas, and that this may, in turn, trigger changes in urban land use. Accessibility, defined as the most straightforward link between urban planning and transportation planning (Giuliano 1995), together with proximity in terms of distance, are the adequate indicators to determine impacts (Transit Cooperative Research Program 2002). In the present study, the before/after accessi- 
bility and the network distance to LRT1 will determine if their changes are related to variations in urban land variables.

\section{Description of the study area}

This section provides a brief description of Manila and the data collected. Some important figures and characteristics of the study that will be useful for understanding the analysis and the results obtained are shown here.

\subsection{Manila in the early $1980 \mathrm{~s}$}

The model in Figure 1 represents Manila in 1980, having similarities with its urban configuration as stated by Brunn and Williams (1983). Starting from the port area, there are several concentric rings characterized by mixed land use adjacent to the core port zone, which is attached to the Central Business District (CBD) with the main government area inside it. The location of new housing and squatter areas outside the core reflects rapid urban growth at the expense of agricultural areas, represented the fringe of the model (Market Gardening Zone).

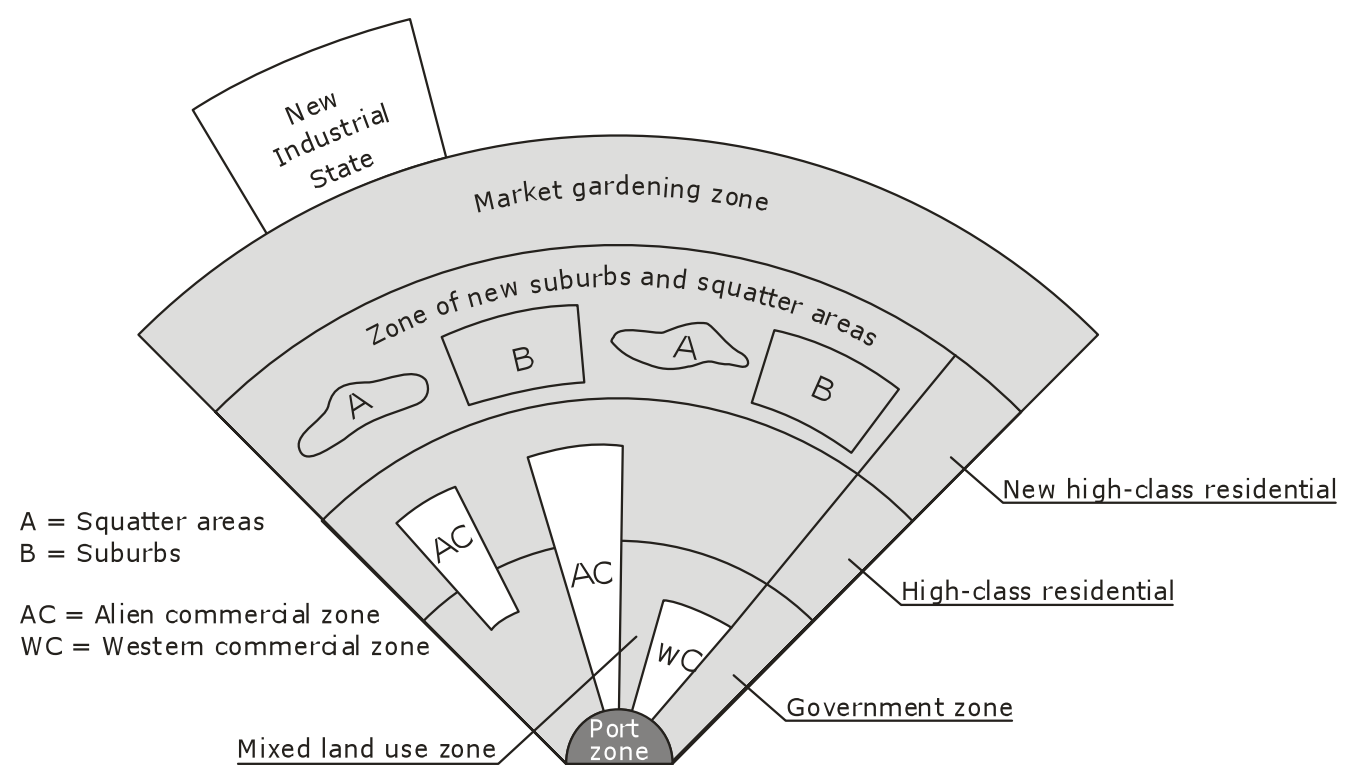

Figure 2: Generalized model of major land use areas in a large Southeast Asian city (from McGee 1967).

Minor commercial centers have been steadily growing inside the core urban area. For instance, the areas of Baclaran and Monumento experienced progressive growth in the number of big malls and minor businesses clustering around major transport terminals. To the city's north in Kalookan municipality, Monumento, in the middle of the junction of EDSA and Rizal Avenues are full of formal and informal transport terminals. They are used by commuters from the northern zones, feeding the crescent of commercial activity. The southern terminal of Baclaran on Taft Avenue plays a similar role for the southern part of the city. In the early 1980s, these terminals and the commercial areas next to the CBD (Carriedo and Blumentritt) were packed with informal commerce. 
The core area is formed by the municipalities of Manila, Kalookan, Pasay and Quezon, Makati, Mandaluyog, and San Juan. During the 1980s, the CBD was attracting more economic development, as it had become the center of a bigger area known as Metro Manila. The 1980s and 1990s were marked by a constant growth of commerce and a decrease in housing, as people preferred to live in new developments such as Calabarzon in the southern part of Manila (Magno-Ballesteros 2000).

Since the early 1980s, Manila has become a huge urban area, among the largest in Southeast Asia (Brunn and Williams 1983). The city's core was almost completely built-up when the LRT1 started in 1984. In 1991, increments in land value outside the study area were around 100-160 percent higher, for residential and commercial properties respectively and from 1993 to 1996 , land values remained practically equal. After 1996, averages showed higher values in the rest of Manila, with higher increments for the same period (Figure 2).

\subsection{Characteristics of the transport}

In the 1970s, transport in Manila was exclusively road-based, made up of jeepneys (a form of paratransit), mini-buses, standard buses, taxis, motorbike tricycles, and bike-powered pedicabs. While large buses operated on arterial or primary roads, jeepneys served trunk and secondary ways. By feeding these two modes, motorized tricycles and pedicabs provided a complementary transport operation service, mainly from established terminals near the most important centers.

From 10.6 million trips/day in 1980, the total increased to 17.5 million in 1996 (Japan International Cooperation Agency 1999). About 79 percent of residents made daily trips in 1996, with an average number of trips of 2.3. Around 98 percent of this total travel demand flowed by roads. Public transportation usage in the 1990s was very high, around 78 percent of all public and semi-public trips (Japan International Cooperation Agency 1999). Jeepneys were the most popular mode regardless of trip purpose: 34 percent used them to go to work, 46 percent to go to school and 21 percent for business trips. Buses primarily served work trips (24\%) and private purposes (13\%). Tricycles were very popular for school (21\%), business (13\%) and private trips (12\%) while taxis were mainly used for business trips (around 14\%).

\subsection{Introduction of the LRT1}

In 1976, a study funded by the World Bank suggested the implementation of an at-street-level LRT in Manila, which was later changed to an elevated configuration due to the impacts at intersections. The project, called Metrorail, was to have revenues by 1993 and was expected to pay for itself by 2005. Implemented in 3.5 years from 1981 to 1985, LRT1 (see Figure 3) was inaugurated in December 1984 with half of the line (Baclaran to Central Station) complete; the full $15 \mathrm{~km}$ length (to Monumento) was complete by 1985 . It runs in the south-north direction along the west side of Manila, crossing the CBD parallel to the bay area, initially with 64 cars with a capacity of 374 passengers ( 81 seated and 293 standing at normal capacity). LRT1's share was initially calculated at around 9 to 10 percent of the total riders and it has a full capacity estimated to be 500000 pass/day at a rate of 27000 pass/hour/direction (18000 in 1985) with speeds of $60 \mathrm{~km} / \mathrm{h}$ (peak) and $30 \mathrm{~km} / \mathrm{h}$ (commercial). The dwell times started at 20-30 seconds in 1985, decreasing later to 10-20 seconds. The flat fare was initially set at 2.5 Philippine pesos (Php) and later increased to $12 \mathrm{Php}$. The line has 18 stations separated by 825 meters on average, located mainly in major commercial (Carriedo, Blumentritt), educational (Pedro 

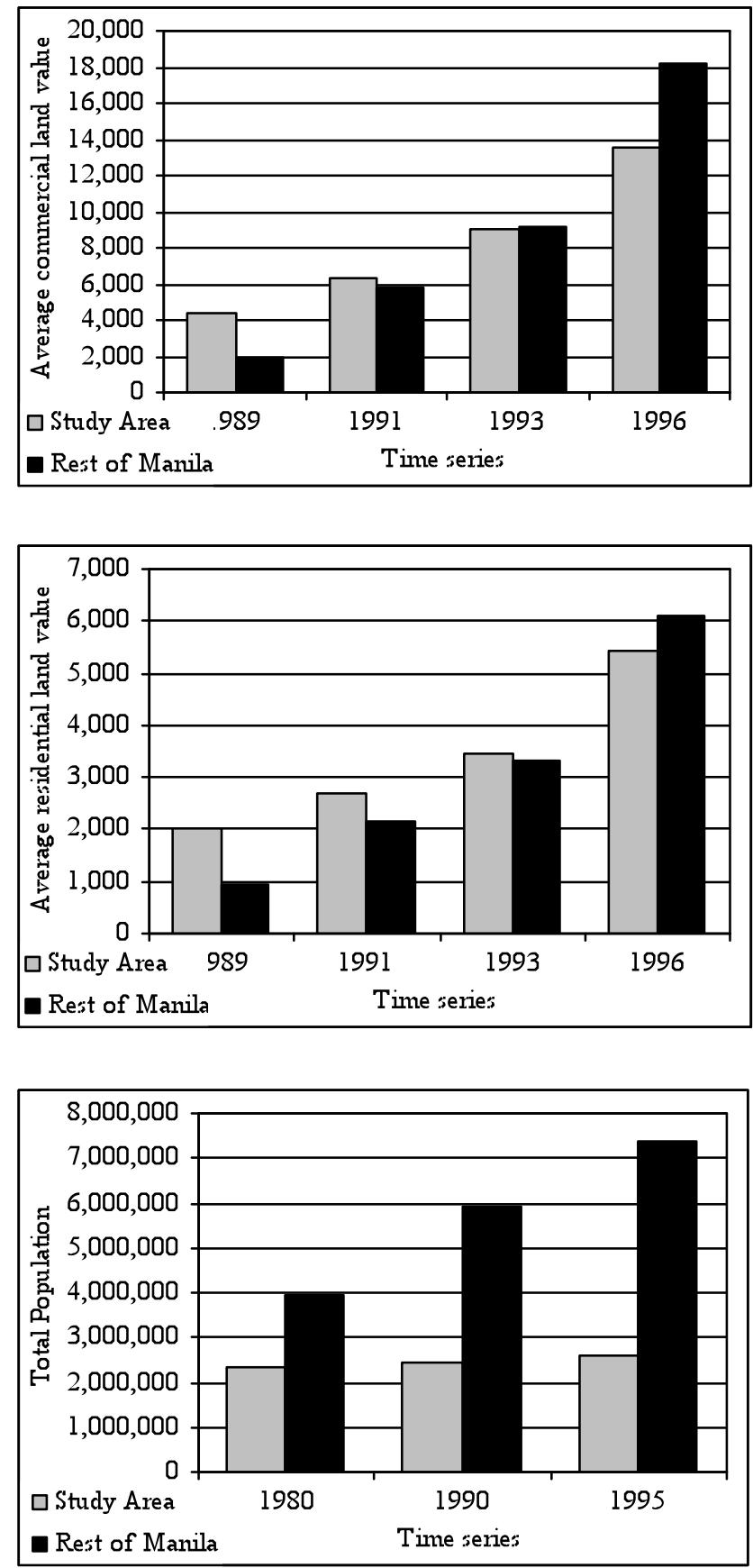

Figure 3: Comparative changes in land values and population in the study area and in the rest of Manila (figures include adjustments due to inflation).

Gil, Vito Cruz), and government (Central) centers. The south end is close to the international airport at Baclaran, in Pasay City, reaching the CBD near Intramuros and connecting Taft and Rizal Avenues. The LRT1's share was around 3 percent of to-work and to-school trips in 1996, which is considered high as the percentage represents only one transport corridor. 


\subsection{The study area}

The study area comprises the LRT 1 corridor from Baclaran to Monumento stations, including the municipalities of Manila, Kalookan, and Pasay. They total 1250 Barangays with six more from Parañaque and Makati municipalities as they are within a $2000 \mathrm{~m}$ buffer around LRT1. This buffer was chosen based on preliminary scattergrams of the urban land variables.

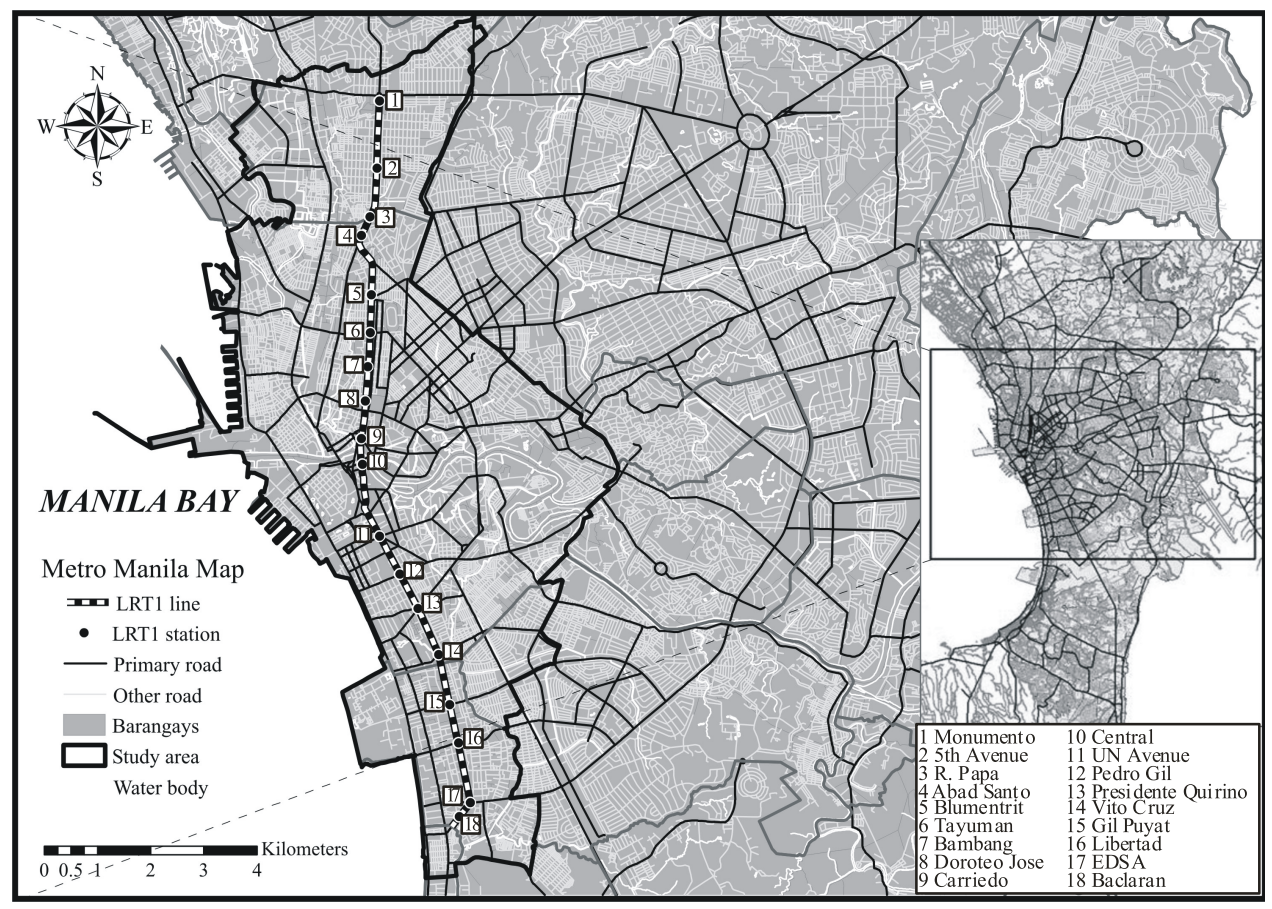

Figure 4: Study area location and LRT1 stations.

\section{Setting the urban land and transport variables}

This section presents a discussion of accessibility measures and the selection of the measure used in the study. It also discusses the initial processing of the data and the setup of the network model for calculating accessibility indexes and distances.

\subsection{Accessibility Measures}

The interaction between two locations in space declines with increasing disutility (lesser accessibility expressed as travel distance, time, cost, or effort). Areas that are more accessible may have a higher interaction potential as they may have a comparative advantage. On the other hand, these areas may be disadvantaged by being unsuitable for some land uses, as they are prone to concentrate many activities and thus generate traffic congestion.

Regarding types of accessibility measures, Geurs and Ritsema (2001) define three basic perspectives. The first is infrastructure-based, useful for analyzing the performance of mass transport systems among others. This perspective considers the access in general terms, based solely on transport capacity. The second is activity-based, which measures accessibility to all activities 
in which an individual engages, incorporating constraints (such as scheduling) and travel characteristics (such as trip chaining) (Dong et al. 2006). This analysis is more suitable for evaluating access available to the population because it measures inhabitants' ability to reach opportunities by means of a given transport mode. The third is utility-based, focused on analyzing the benefits that people derive from access to spatially distributed activities; this perspective is mainly applied in economic studies (Geurs and van Wee 2004).

This study uses an infrastructure-based accessibility measure, as the objective is to determine access at one location to all others inside the study area based on the performance of the network before and after the introduction of LRT1. According to Geurs and van Wee (2004), infrastructure-based accessibility measures play an important role in current transport policies in many countries as several measures are used to describe the functioning of the transport system, such as travel times, congestion, and operating speed on the road network. Obviously, the advantages of this type of accessibility measure are its ease of implementation and communicability; the necessary data and (transport) models are often readily available and measures are easy for researchers and policy makers to interpret. Because infrastructure-based accessibility measures may not incorporate the land use component (or consider it homogeneous), the variable produced better represents the performance of transport per se without the influence of other factors. This is useful for comparing pure transport indicators against other variables related to urban areas.

Gutierrez et al. (1998) identified geographical location as a decisive influencing factor regarding accessibility indicators. The authors described several accessibility measures that prove the influence of spatial determinants. Although these may be unsuitable for determining transport needs in a particular region, they are useful when analyzing a scenario in which accessibility changes between two periods. This scenario matches the longitudinal schema and provides the ideal framework for the empirical before/after analysis proposed in the present study. Nevertheless, Gutierrez et al. also point out that this approach may not provide a measure of the relative ease of access-in terms of network efficiency-in each of the two points in time. To tackle this, the present study also includes (in addition to the scenario after the introduction of LRT1) a scenario determined by the accessibility provided by jeepneys and buses prior to the line's opening in 1984. Both are assessed together with the rest of public transport (which includes walking to/from stops) using the same indicators and spatial units (the Barangays) within a network with impedances assigned for each link. The 1256 Barangays selected are the centers of potential travel for which an accessibility index is calculated.

For the present accessibility analysis, an exponential distance decay function is used. Fotheringham (1982) establishes that exponential functions are more accurate for measuring trips inside urban areas, while power functions perform better for the interurban level. Therefore, accessibility is expressed as:

$$
A_{i}=\sum_{j=1}^{n} D_{j} e^{-\beta \cdot L_{i j}}
$$

where $D_{j}$ is the attractiveness of location $j, \beta$ is the distance decay coefficient (DDC), $L_{i j}$ the length of link $i j$, and $n$ the number of locations.

The aim of this study is to test the performance of the transport network before and after the introduction of LRT. An indicator of how well the transport network (purely in those terms) provides access to all sampling areas is required, in order to see if changes in performance 
correspond with changes in these areas. The calculation considers an equal $D_{j}$ attractiveness factor for all sampling units. The attraction by the land use side can be attributed to several factors, including massive commercial or housing development. Moreover, data on changes in attraction for each sampling unit before and after LRT1 were not available - and even if they had been available, their inclusion would have made it difficult to assess which improvements in accessibility were due mainly to LRT1 (or at least to its influence on the existing transport modes). Besides, attractiveness factors per se would be enough for assessing the changes in land use variables. By using an accessibility measure based on network performance, we can calculate the accessibility improvements generated solely by the LRT1 and later, assess whether these improvements correspond with changes in the land variables chosen.

The results will yield the accessibility value of each sampling unit (area) by means of the transport network before and after the addition of LRT. This is done to evaluate changes in land variables related to improvements introduced by the LRT itself (excluding natural changes in attraction by the land uses in the study area). The objective is the assessment of both the situation before LRT 1 and the added accessibility it introduced, measured as indicators.

The value of the DDC is determined by an exponential regression using travel distances (willingness to travel by mode) and the number of people traveling based on data from the Metro Manila Urban Transport Integration Study (Japan International Cooperation Agency 1999). A generalized-cost model is adapted for calculating travel impedances for each link in the network, with three components: travel time (including waiting time by mode), total delay time at intersections (by semaphores/turns), and monetary (out of pocket) costs. The last, averaged per length unit and differentiated by transport mode, ranges from zero for walking to $6 \mathrm{PhP}$ as a flat fare (1 $\mathrm{PhP}=\mathrm{US} \$ 0.23$ in 1996) for taking the LRT1. These and other costs were converted to time using mean income per time unit for regular workers in Manila, while time impedances are added up directly. The final formula, in which results are expressed in time units, is:

$$
I_{i j}=T_{i j}+N_{j}+F_{m}
$$

where $N_{j}$ represents mean time at node $j$ (intersection) due to semaphores and/or congestion when crossing it, dependent on the road class; $T_{i j}$ are the time units to travel the link (often referred to as in-vehicle time), which is:

$$
T_{i j}=\frac{L_{i j}}{S_{m}}
$$

where $L_{i j}$ represents the actual link measure in longitude units and $S_{m}$ is the speed by mode of transport expressed in distance units over time and $F_{m}$ is the monetary price for traveling the link, averaged to longitude units by transport mode. It is expressed as:

$$
F_{m}=\frac{L_{i j} P}{W}
$$

where $L_{i j}$ is the length of the link $i j ; P$ is the fare for a transport mode (in PhP per distance unit); and $W$ is the mean income per time unit for regular workers in Manila. The results of this calculation are in time units. 


\subsection{Building the transport network}

The impedances are loaded onto the network according to the route systems for the two main transport modes in the study area: buses and jeepneys. As the LRT1 has an elevated infrastructure, special impedance values are set for links connecting the jeepneys/bus network (Figure 4), representing average access/egress characteristics to/from LRT1's stations.

Network distances from each Barangay to the LRT1 line are also calculated and converted into classes (distance ranges) as the second independent variable. To assess impacts, both accessibility indexes and the distances are compared against five urban land variables: residential and commercial land values; housing and commercial land use; and population density. The analysis is carried out using statistical correlations and simple/multiple regressions.

\subsection{Accessibility Results}

The differences in values for the scenarios before and after LRT1 are evident, as are the relatively high accessibility values north of the line due to the concentration of jeepney/bus terminals as one of the most important commuting points in Manila.

For a better graphic representation, the resulting indexes are organized in classes, set for both accessibility before LRT1 and after LRT1 (accessibility indexes by buses/jeepneys and LRT1 added together), as shown in Figure 5.

\subsection{Setting the scenarios and the data}

As independent variables, both the effect of accessibility (based on network impedances) and the proximity (in terms of distance) are correlated with the urban land variables. This is done in a before-and-after schema, representing scenarios without and with the LRT1, respectively. The data $^{1}$ were collected for different time series in a longitudinal analysis from 1986 to 1996 and then processed to build a database at Barangay ${ }^{2}$ level, also including secondary data for setting up a transport network for the accessibility variable within GIS. Most of this data come from the extensive MMUTIS study (Japan International Cooperation Agency 1999) by NCTS ${ }^{3}$. Other qualitative data were collected directly in the field as well as a general overview of the performance of the LRT1.

\section{The impacts of LRT1 on urban land in Manila}

The main analysis involves quantifying 15 combinations of variables as depicted in Table 1 , using Pearson's correlation and simple regression analysis for each combination. Three-dimensional GIS maps help to visualize the relationships, if any. These maps present two data variables within the same map: one via color and the other via volumetric shapes or extrusions, shown in perspective. In addition, and only for the variables that show consistency in the correlations, a single/multiple regression analysis (MRA) was applied, using both accessibility after LRT1 and distances as predictors.

\footnotetext{
${ }^{1}$ The Bureau of Internal Revenue (BIR) provided land values by activity at street-level from 1989 to 1996 . A 1986 land-use map, geographic layers and transportation network/data came from MMUTIS. Population figures were given by the National Statistics Office (NSO).

${ }^{2}$ Minimal census and administrative unit in urban areas of the Philippines.

${ }^{3}$ National Centre for Transportation Studies, University of the Philippines-Diliman, Quezon City.
} 


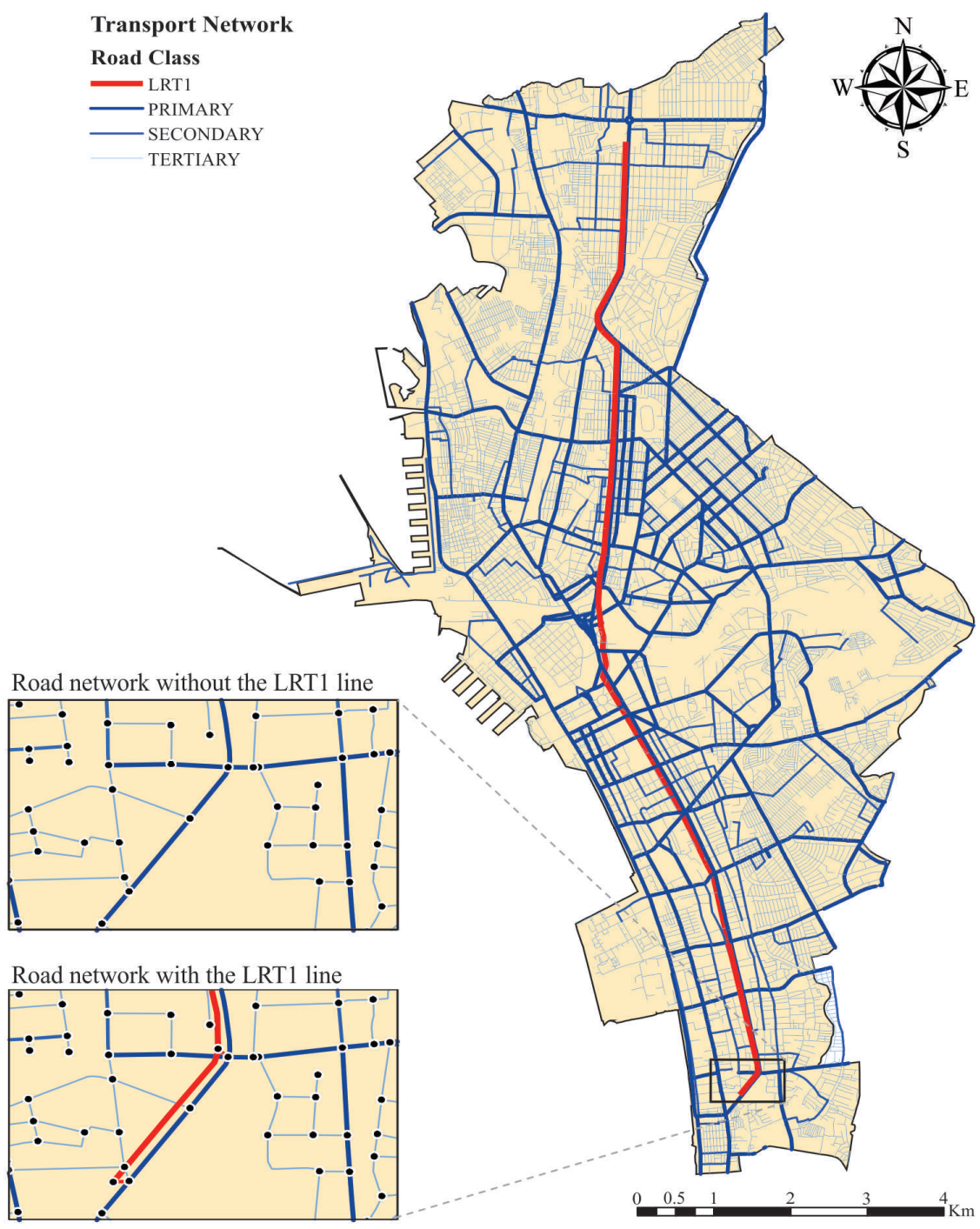

Figure 5: Transport network for accessibility model calculation, showing scenario details.

Histograms were created for each variable to determine possible sampling errors and scattergrams to show the dispersion patterns. All variables had consistent results using descriptive statistics as they belonged to a single sampling set, with some evidence of values clustering towards linearity. Collinearity tests for both MRA's predictors yielded consistent results.

The dependent variables were further processed to show changes within time series, producing multiple outputs for each time sequence. There are four indicators for each commercial and residential land value, for the periods 1989-91, 1991-93, 1993-96, and 1989-96; three for each housing and commercial land use area change, for 1985-91, 1991-97, and the whole 1985-97 period; and three for changes in population density for 1980-90, 1990-95, and 1980-95-all analyzed with the three independent variables. A summary of results is shown in Tables 2, 3, and 4. 


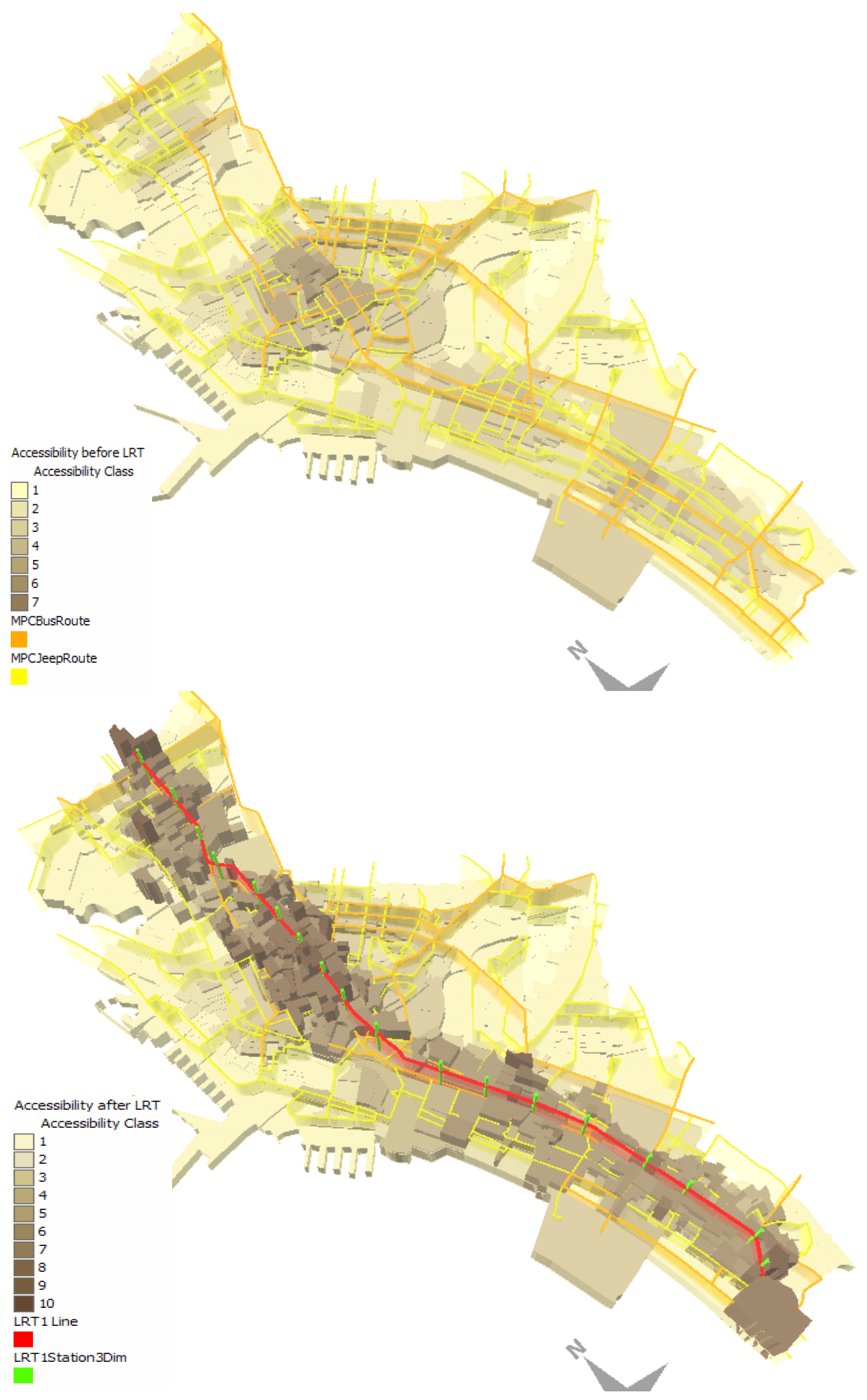

Figure 6: Results of the accessibility calculation showing the differences before (top) and after LRT1 (bottom). 
Table 1: Scheme of variables and relationships for impact analysis.

\begin{tabular}{lccc}
\hline & \multicolumn{2}{c}{ Accessibility } & $\begin{array}{c}\text { Distance } \\
\text { to LRT1 }\end{array}$ \\
\cline { 2 - 3 } & Before LRT1 (CTS) & After LRT1 & \\
\hline Land value: & $*$ & $*$ & $*$ \\
Residential & $*$ & $*$ & $*$ \\
Commercial & & & \\
Land use: & $*$ & $*$ & $*$ \\
Housing & $*$ & $*$ & $*$ \\
Commercial & & & \\
Density: & $*$ & $*$ & $*$ \\
Population & $*$ & & \\
\hline
\end{tabular}

\subsection{Land value analysis}

Land values have a better correlation with accessibility after LRT, showing higher coefficients than in the pre-LRT1 scenario and rising coefficients along the time series (Table 2). The correlations for commercial land values show consistency except for the 1993-96 period ${ }^{4}$, though the results are quite marginal and not as strong as the ones for residential values. The latter also show a tendency to grow steadily in the time series, with the highest value in the overall 1989-96 period. Compared to the pre-LRT1 scenario, the coefficients are not only stronger but also positive, growing towards a stronger linearity in the time series. The regressions show that there is only a limited possibility of predicting land values based on accessibility. This predictability is only significant for residential land values, which have better coefficients overall.

Figure 7 shows the strength of the relationship between accessibility post-LRT1 and residential land values. Most of the high residential land values (darker tones) are clustered and related to high accessibility changes (higher extrusions), while lighter tones representing low land values are generally associated with lower heights. Some evident mismatch between colors and extrusion heights (higher extrusions with lighter colors and vice versa) illustrates the weak correlation found.

The analysis of distances to LRT1 and land values shows a strong negative relationship, an inverse correlation with consistency (Table 3). The coefficients are also higher, showing the tendency for residential land values decrease with distance from LRT1. Once more, coefficients get stronger as the time series progresses, meaning that the longer LRT1 operates in Manila, the lower the value of residential land close to it. Scattergrams show more negative residential land value changes adjacent to the LRT1 line, especially in the 1993-96 and 1989-96 intervals (see Section 6.2). The results for commercial land values have far less consistency and the correlations have roughly the same value across the time series, though there is a slight decrease. Figure 8 illustrates the relationship between distance from LRT1 and commercial land values, showing the lack of a clear clustering pattern as all results point towards a lack of correlation (high volumes with darker tones and vice versa) between the two variables.

\footnotetext{
${ }^{4}$ This might be result of the political instability brought on by an attempted coup d'état against President Aquino and the eruption of Mount Pinatubo followed by an earthquake in Metro Manila affecting the Philippine economy in the early 1990s (Magno-Ballesteros 2000).
} 


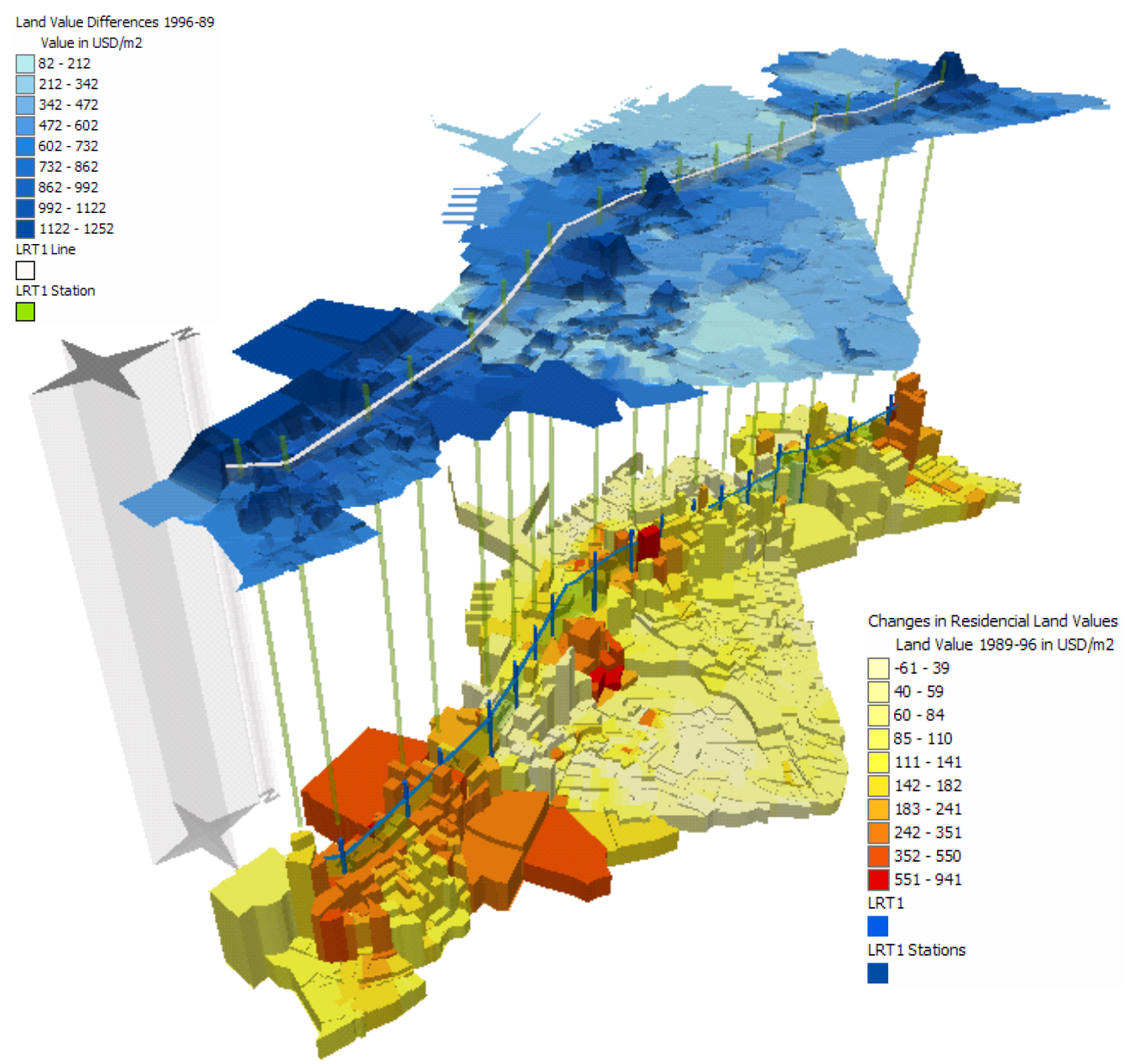

Figure 7: 3D map relating accessibility after construction of LRT1 (extrusion volumes) and residential land values (colour scale shown in corresponding legend) with overall changes in land values (upper map).

Multiple regression analysis shows strength and consistency in predicting residential land values using accessibility after the construction of LRT1 and the distance to the line (Table 4). The results of the 1989-91 series are almost identical to the ones for the same period in the simple regression (Table 3), demonstrating the weakness of the accessibility component for this series in the multiple regression. However, the coefficients are the highest of all the variables and predictability improves over the time series, reinforcing the previous results and pointing towards an increased influence of accessibility and distance with time after LRT1 started its commercial operation. The overall result for the 1989-96 time series shows a consistent influence of the combined accessibility and distance of almost 20 percent (the adjusted $r^{2}$ ) of the variance in residential land values, with partial results for the other series ranging from 6 to 14 percent. Commercial values were not tested, as results show a low correlation between variables. 


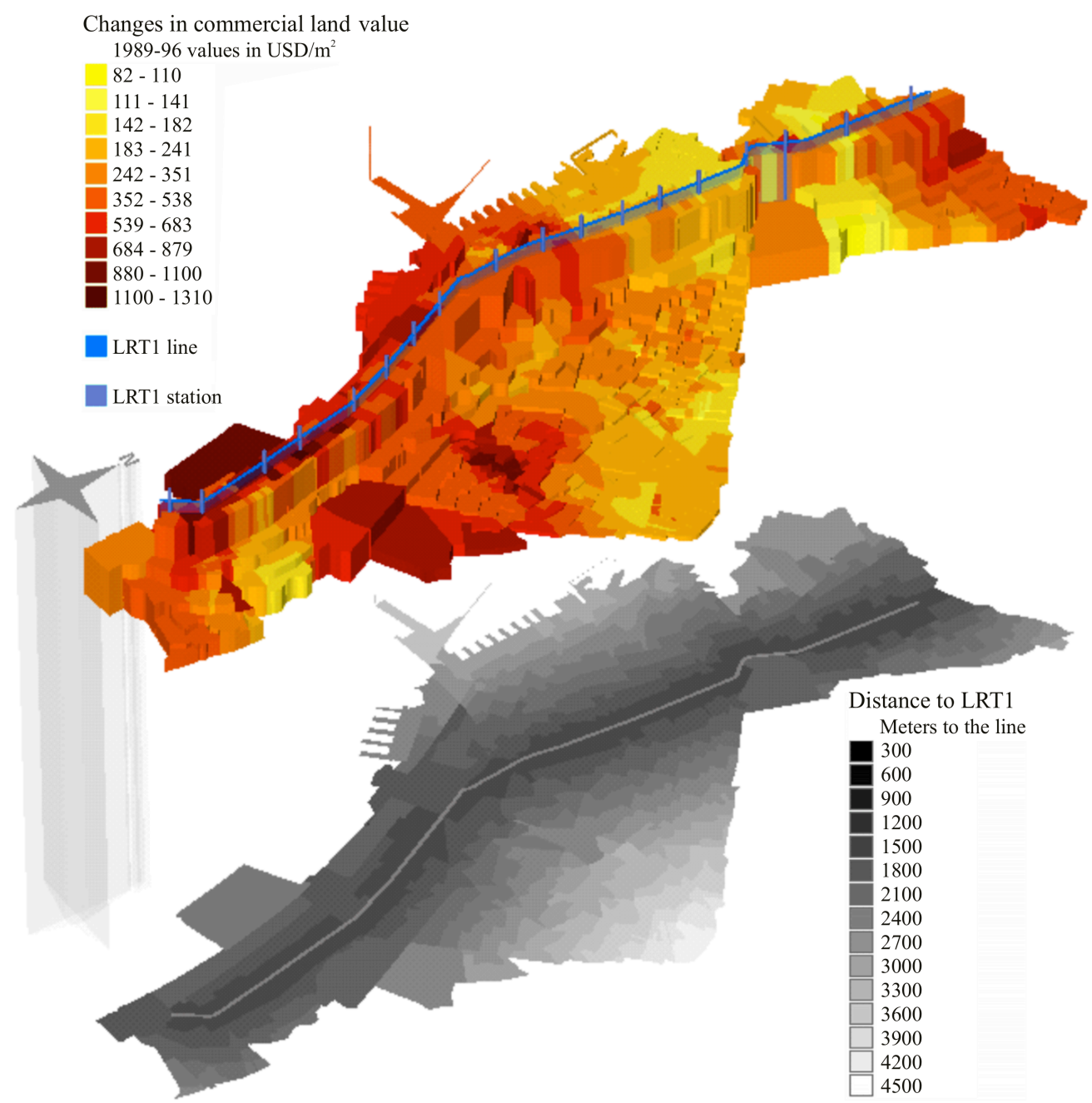

Figure 8: 3D map relating distance to LRT1 (extrusions) and commercial land values (red/yellow tones).

\subsection{Land Use}

There is no relationship between housing or commercial land use and the independent variables. Once again, the comparison between scenarios shows lower correlation with accessibility before the construction of LRT1 than after. In the latter scenario, there is no correlation with consistency for both land uses; the weakness of the coefficients indicate that no relationship exists. However, there is a better correspondence of values for the scenario with the LRT, where the correlation coefficients have a higher significance level, though still extremely weak. The results of the regression analysis is the same for both independent variables, stressing the lack of correlation with land uses. 


\subsection{Population Density}

Contrary to the previous observations, the results show consistency for population density and accessibility before LRT1 than after it (Table 2). The negative correlation with accessibility after LRT1 is not only weak but also inconsistent for the 1990-95 time series. If consistent, this result could suggest that higher accessibility determines lower population densities and vice versa. However, all correlations between population density and distance to LRT 1 show a clear lack of correspondence and the regression results support these findings. The regressions show the same the results and inconsistencies, pointing towards a lack of influence of the independent variables over changes in population in Manila.

\section{Discussion}

\subsection{Results in the context of the study area}

As explained in Section 3, the city's core was completely built up at the time LRT1 was implemented across this area, causing its impacts to be more complex and limited in extent. The land market in Manila constrained real estate development in the built-up area as opposed to areas around fringes of the city. However, not all land value changes outside the study area can be compared, as the fringes have the lowest values prior to urban development. A preference for more space, free of pollution and traffic congestion would make them more attractive to development. This scenario suggests a limited capability for land development in the city's core within the time frame of this study, which may have affected the results.

The massive presence of dwellings in any urban area compared with commercial buildings has provided a better way of correlating variables. Accessibility and distance, when related to land values, will always have a better level of comparability with more sampling present in the study area as is the case of residential land values. The smaller number of sampling units of commercial land values will therefore be less easy to correlate and its changes, even in a smaller scale, will have less consistency for the analysis. This may explain the lesser degree of correspondence shown by this variable.

Moreover, the marginal results for commercial land use may be attributable to location factors, as commerce has great influence through economies of agglomeration and speculation in focalized clusters. Despite this, a micro-urban analysis can distinguish some patronage of LRT1 stations over major changes in commercial areas. The stations at both line's extremes (Baclaran and EDSA to the south, Monumento and Fifth Avenue to the north) have different extents of their adjacent commercial area, as well as by the LRT1's center (Gil Puyat, Vito Cruz and President Quirino stations). The most remarkable case is Monumento, where commercial land use changes in surrounding neighborhood are among the highest in the study area due to the large volume of commuting trips. Nevertheless, these areas are not large enough to reveal consistent relationships with accessibility indexes at the macro-urban level and, as seen, major changes are weakly related to the whole LRT 1 corridor.

Another influencing factor is the progressive reduction in the amount of housing-and thus population density-in Manila's core as intense commercial activities have pushed highand mid-income classes to relocate away from their traditional dwellings. A rise in land value such as that generated by commercial demand tends to trigger preferences for inexpensive housing away from fast-growing (and possibly constrained) commercial nodes in the CBD. This may 


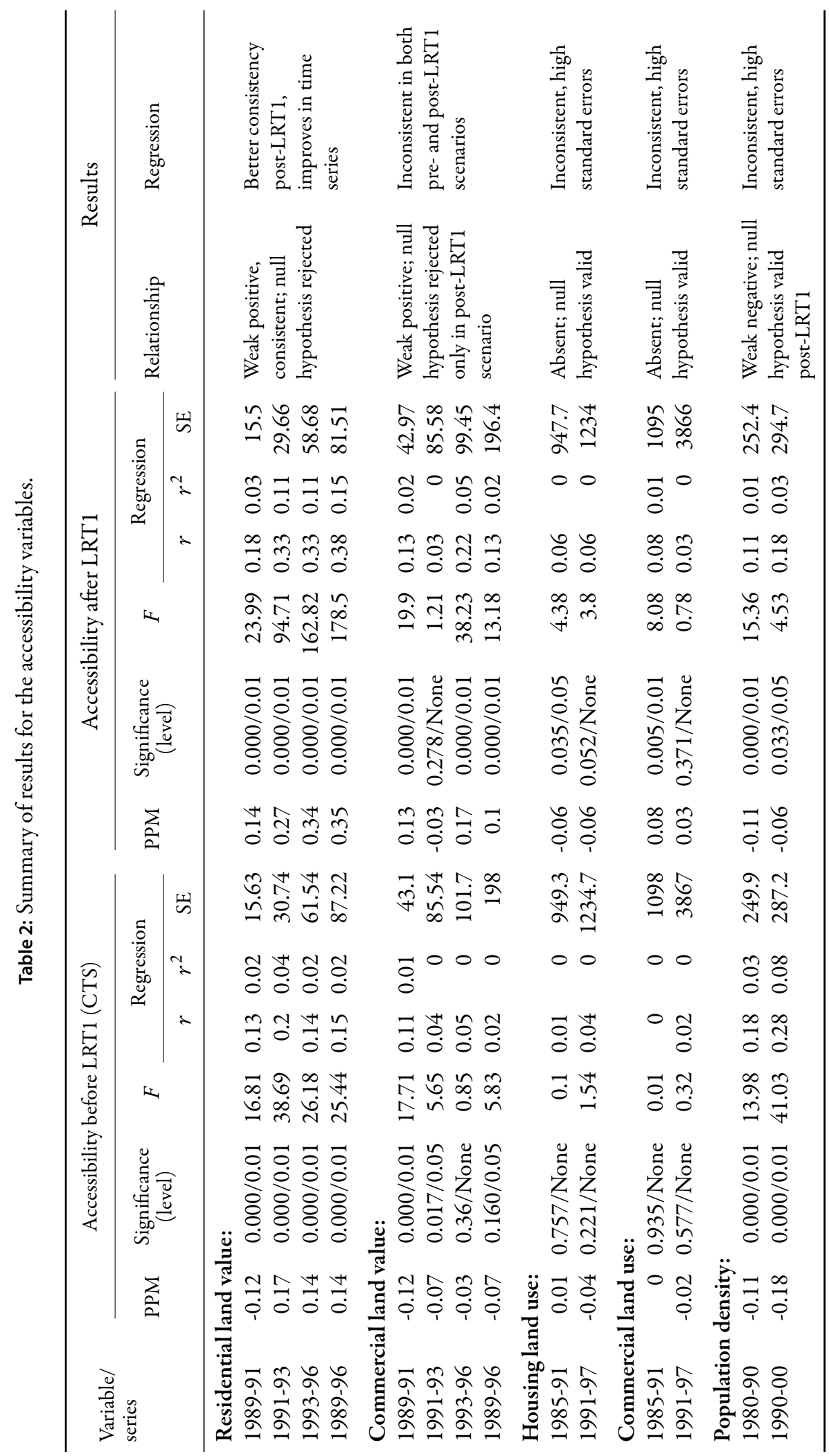


Table 3: Summary of results for the distance variable.

\begin{tabular}{|c|c|c|c|c|c|c|c|c|}
\hline \multirow{3}{*}{$\begin{array}{l}\text { Variable/ } \\
\text { series }\end{array}$} & \multicolumn{6}{|c|}{ Distance to LRT1 } & \multicolumn{2}{|c|}{ Results } \\
\hline & \multirow{2}{*}{ PPM } & \multirow{2}{*}{$\begin{array}{l}\text { Significance } \\
\text { (level) }\end{array}$} & \multirow{2}{*}{$F$} & \multicolumn{3}{|c|}{ Regression } & \multirow{2}{*}{ Relationship } & \multirow{2}{*}{ Regression } \\
\hline & & & & $r$ & $r^{2}$ & SE & & \\
\hline
\end{tabular}

Residential land value:

$\begin{array}{lllllllll}1989-91 & -0.21 & 0.000 / 0.01 & 59.01 & 0.25 & 0.06 & 15.26 & \text { Weak negative, } & \text { Very consistent, clearly } \\ 1991-93 & -0.29 & 0.000 / 0.01 & 110.86 & 0.34 & 0.12 & 29.46 & \text { consistent; null } & \text { improves in time series; } \\ 1993-96 & -0.38 & 0.000 / 0.01 & 207.76 & 0.37 & 0.13 & 57.86 & \text { hypothesis rejected } & \text { better coefficients than } \\ 1989-96 & -0.40 & 0.000 / 0.01 & 238.86 & 0.42 & 0.18 & 79.82 & & \text { accessibility }\end{array}$

Commercial land value:

$\begin{array}{rrrrrrrll}1989-91 & -0.26 & 0.000 / 0.01 & 90.92 & 0.27 & 0.07 & 41.79 & \text { Weak negative, } & \text { Consistent except for } \\ 1991-93 & -0.03 & 0.318 / \text { None } & 0.98 & 0.03 & 0.00 & 85.56 & \text { consistent; null } & 1991-93 \text {, coefficients } \\ 1993-96 & -0.25 & 0.000 / 0.01 & 83.60 & 0.28 & 0.08 & 97.79 & \text { hypothesis rejected } & \text { roughly same in other } \\ 1989-96 & -0.20 & 0.000 / 0.01 & 50.63 & 0.22 & 0.05 & 193.40 & & \text { series }\end{array}$

Housing land use:

$\begin{array}{rrrrrrrr}1985-91 & 0.11 & 0.000 / 0.01 & 16.51 & 0.11 & 0.01 & 943.10 & \text { Very weak positive } \\ 1991-97 & 0.07 & 0.009 / 0.01 & 6.90 & 0.07 & 0.01 & 1232.10 & \end{array}$

Better in 1985-91, inconsistent in 1991-97; high standard errors

\section{Commercial land use:}

$\begin{array}{rrrrrrrl}1985-91 & -0.11 & 0.000 / 0.01 & 15.08 & 0.11 & 0.01 & 1091.70 & \text { Absent; partially } \\ 1991-97 & -0.05 & 0.091 / \text { None } & 2.90 & 0.05 & 0.00 & 3863.00 & \text { valid null hypothesis }\end{array}$

Better in 1985-91, inconsistent 1991-97; high standard errors

Population density:

\begin{tabular}{lllllllll}
$1980-90$ & 0.04 & $0.124 /$ None & 2.32 & 0.04 & 0.00 & 253.70 & Absent; valid null & $\begin{array}{l}\text { Inconsistent; high } \\
\text { standard errors }\end{array}$ \\
\hline $1990-95$ & 0.04 & $0.132 /$ None & 2.22 & 0.04 & 0.00 & 195.50 & hypothesis & \\
\hline
\end{tabular}

Table 4: Summary of results of multiple regression analysis for residential land value.

\begin{tabular}{|c|c|c|c|c|c|c|c|c|c|c|c|c|}
\hline \multirow{2}{*}{$\begin{array}{l}\text { Variable/ } \\
\text { series }\end{array}$} & \multicolumn{4}{|c|}{$\begin{array}{l}\text { Predictors: Distance to \& } \\
\text { accessibility after LRT1 }\end{array}$} & \multicolumn{5}{|c|}{ Regression } & \multicolumn{3}{|c|}{ Residuals } \\
\hline & $r$ & $r^{2}$ & Adj. & SE & $\begin{array}{l}\text { Sum of } \\
\text { Squares }\end{array}$ & $d f$ & $\begin{array}{l}\text { Mean } \\
\text { Square }\end{array}$ & $F$ & Sig. & $\begin{array}{l}\text { Sum of } \\
\text { Squares }\end{array}$ & $d f$ & $\begin{array}{l}\text { Mean } \\
\text { Square }\end{array}$ \\
\hline \multicolumn{13}{|c|}{ Residential land value: } \\
\hline $1989-91$ & 0.251 & 0.063 & 0.061 & 15.27 & 19590.3 & 2 & 9795.2 & 41.99 & 0.000 & 292261.5 & 1253 & 233.2 \\
\hline $1991-93$ & 0.364 & 0.132 & 0.131 & 29.25 & 163653.0 & 2 & 81826.5 & 95.65 & 0.000 & 1071908.5 & 1253 & 855.5 \\
\hline $1993-96$ & 0.378 & 0.143 & 0.142 & 57.55 & 692520.9 & 2 & 346260.4 & 104.54 & 0.000 & 4150270.1 & 1253 & 3312.3 \\
\hline $1989-96$ & 0.439 & 0.193 & 0.192 & 79.23 & 1881382.5 & 2 & 940691.2 & 149.86 & 0.000 & 7865289.1 & 1253 & 6277.2 \\
\hline
\end{tabular}

\section{Relationship:}

Clear pattern of improvement in the regressions on time series. The fitting of the models is the best on the overall analysis. Residuals are high, though still acceptable. 
partly explain the small impact of LRT1 on land uses, especially housing. Although some major changes have occurred next to stations, this is just due to the commercial expansion at Baclaran or Gil Puyat stations mentioned above. This commercial growth depended on transport (both private and public) and led to a reduction of housing and industrial areas as land was converted to shopping malls in the 1990s (Magno-Ballesteros 2000).

Population density had a particular development in Manila during the time frame of the present study. As explained in Section 3, densities within the study area increased less than in the rest of Manila. In the former, the Barangay density only increased to $180 \mathrm{hha}$. while in the latter the population nearly doubled from a mean of 6102 to 11441 habitants per Barangay. This may be evidence of a low level of housing development or of population displacements to locations outside the study area by the time LRT1 entered service. The statistics also show a decrease in housing area, pointing towards a higher densification within existing dwellings to maintain population levels. The inconsistency when correlating accessibility and distances with population density changes could have an explanation as this highly influenced environment that may have limited the LRT1's effects.

\subsection{Related theory and explanation of results}

As mentioned above, the displacement of housing from the central area to the newly developed outer parts of (among others) Quezon and Kalookan municipalities caused a decrease in population figures around the LRT1 line. This change in the residential area preferences of Manila residents during the 1980s and 1990s was explained by Magno-Ballesteros (2000). As mentioned in Section 2, increasing accessibility may not change previously existing tendencies but rather amplify them. If an area is undergoing expansion, mass transport can accelerate it, but if an area is declining, mass transport may help stabilization but it is unlikely to reverse the decline. The pattern of population loss in Manilass core continued after the LRT1 entered services.

Most findings show a correspondence with related theory in situations where mass transport has demonstrated to generate impacts over urban land. In general, the studies reviewed in Section 2-especially the research by Cervero and Wu (1998) and Wegener and Fürst (1999) show that factors other than accessibility increasingly influence metropolitan location decisions, concluding that the influence of urban-rail transport on land development is very limited. With respect to the weak correlations found, the small and variable impact of urban rail investment is also influenced by these non-accessibility factors as additional infrastructure (particularly where networks are already well developed) has little effect on the overall level of accessibility. The anticipated large accessibility increases due to the introduction of the LRT1 had less influence due to the fact that accessibility was already good before the LRT1 was introduced. In Manila during the 1980s and 1990s, the large number of small transport units (jeepneys, aircons, etc.) provided seamless accessibility (Wright and Hook 2007).

As seen in the studies reviewed, the effects identified may only be significant where accessibility is low and will have a limited influence in areas that have relatively good access, the so-called "ubiquitous accessibility." This is especially true for congested traditional cities, such as Manila. Where time savings are made, property values are likely to increase. If the change in accessibility is large enough — as in the case of the LRT1 — time savings will be noticeable by at

${ }^{5}$ Although it may have maintained population figures, this was not evidenced by the study as it would need more data. 
least some population sectors, whereas public-transport investments that do not significantly reduce travel times will have little influence. This is logical in light of the limited relationship between urban land changes and accessibility/proximity variable for LRT1. In both cases, it implies that the brute mechanics of distance and transport cost may be declining in importance.

Transport investments such as LRT1 are often necessary but not sufficient to generate development. This development would be considerable in the case of areas lacking transport infrastructure or in "advanced" transport networks, where there is a significant step of accessibility change or solutions to major transport conflicts, e.g. network bottlenecks. Hall and Marshall (2002) also noted two particularly important contextual items regarding transport investment on development: first, infrastructure investment has led to land use development in buoyant economies; second, the regulatory context-such as planning controls-implies that public transport-led development tends to flourish where policies favor public TOD. Relevant contextual factors include complementary zoning, taxation policies, land availability, and a "hospitable" setting. In Manila, no such controls to profit the improvements in accessibility by LRT1 were applied. As the first mass transport system in the Philippines, LRT1 may have surprised institutions that were unaware of the need to set a TOD framework to favor this influence. It seems that the priority was given to the recovery of investment through fare box revenues by demand catching, purely the transport planning point of view without an integrated perspective. In this sense, an appropriate environment for the maximization of urban land changes due to the LRT1's improvements is also necessary. According to the literature reviewed in Section 2, LRT1 may have a strong influence on the location, intensity, and timing of new development if it had been supported by the appropriate planning guidelines. This context is of extreme importance and may only lead to positive new urban land developments where stringent land use controls are employed to direct changes, which was not the case for the LRT1 in Manila.

Another decisive factor mentioned in Section 2 is the provision of public infrastructure and financial incentives to attract and support development around stations, which unfortunately was not done in Manila. The development of economic activities cannot be solely explained by well-developed transport facilities. This is due to the inability of transport facilities to provide users a revenue per se. In addition, the lack of a TOD approach before and soon after the construction of LRT1 (partially rectified only when the line had been operating for several years) is in line with the limited the extent of impacts on urban land found in this study.

Finally, LRT1 may have had two different and opposing effects on residential land values. First, a closer proximity to the line may increase property values, implying a declining price gradient on incremental distance from its stations. Second, properties adjacent to the line may experience nuisances that lower their value, evidenced in the correlations between distance to the LRT1 line and residential land values (see Section 5.1). It is widely known that noise, vibration, congestion, visual impacts, and increasing commercial activity (among other factors) such as may be found next to a mass transport station may have some negative impacts on residential land values. As shown in Figure 9, the analysis of the scattergrams of distance to LRT1 and land values supports these observations. Changes in land values are negative immediately adjacent to the line (the curve below the Y-axis); the negative effect weakens with distance from the LRT1, until it disappears by the $900 \mathrm{~m}$ range. These observations highlight disbenefits for residential activities generated by the opening of LRT1 in the early 1980s. A study by Landis et al. (1994) obtained a similar result, finding evidence of negative externalities within a few 
hundred meters of stations. For commercial land values, these disbenefits are smaller, though still considerable. However, in this case, some of the effects that would be disadvantages in residential areas could be seen as advantages: proximity to railway lines means more access and thus more potential profitability in land use terms, especially for housing for low-income populations that are largely dependent on public transport. In that sense, Du and Mulley (2007), in research on house values and accessibility by metro lines in the Tyne and Wear region in the United Kingdom, found no significant negative effects within $200 \mathrm{~m}$ of a station. This contradiction emphasizes the variability of results across different study areas and the necessity of including potential side effects, planning factors, and policies applied when analyzing the relationship of transport and urban land, which has proved to be extremely complex.
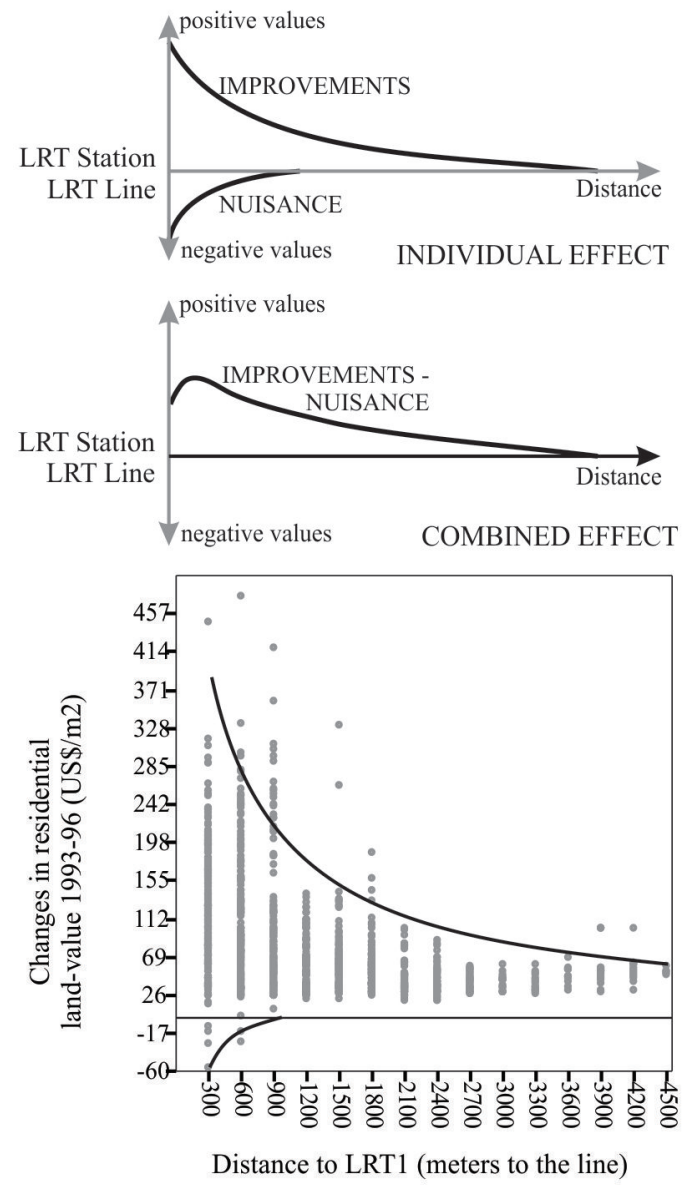

Figure 9: Distances to LRT1 and residential land values and correspondence with other observed effects. Adapted from Geurs and Ritsema (2001).

\section{Conclusions and further research}

This study has found evidence of consistent relationships between LRT1 and some urban land indicators. Accessibility and distance have a consistent correlation with changes in the value of land (particularly residential land) and improvements can be seen within time series. At 
the same time, in the pre-LRT1 scenario (accessibility only by jeepneys/buses), this correlation is either absent or much weaker. Further, no correlation is evident between accessibility or distance from LRT1 and changes in housing/commercial land uses or population density. This is in accordance with similar findings in related research, which have ranged from a simple lack of systematic influence to a weak though consistent link.

The assessment of LRT1's influence on land values proved to be limited. As seen in related studies, accessibility and proximity to public transport are only part of the overall hedonic formula influencing land values. This formula also includes factors such as consumer preferences, proximity to public services (health, education, etc.), urban landscape, environment/neighborhood quality, land's economic potential, etc. On the other hand, the more complex land use factors of location (such as speculation or land availability) or failure to adequately apply TOD policies may have caused the inconsistency between the LRT1 indicators and land use changes.

Similarly, population densities showed changes uncorrelated with these indicators. Location factors, such as preferences for open space free of congestion or pollution, drove migration out of Manila's core (the study area) to newly developed northern and southern areas. With no incentives, this trend could not be counteracted by LRT1 influences; previous research has also shown that mass transport might not have the capacity to change such trends, though it might further strengthen them. The incapacity of LRT1 to influence settlement patterns by itself partly explains the absence of correlations with population densities. In general, the study measured the impacts of LRT1 on the selected urban land variables in the developing city of Manila, finding some degree of strength in the correlations and regressions with the model used.

As this research only covered some transport-related variables, the next task would be to assess other particularly important factors. The list includes negative effects such as environmental or traffic impacts. At the micro-urban scale, the analysis of pedestrian flows or bus terminals around LRT 1 stations may shed some light on the subject. To understand how the impacts vary depending on the economic setting of the study area, it may be advisable to focus on emerging economies, as there is more research on the impacts of mass transport in developed countries. Additionally, it would be important to differentiate typologies, conducting separate research for subways, grade-level systems, elevated lines, etc., as their impacts may be quite different. Other accessibility measures can be incorporated in future studies as well.

Finally, the evidenced impacts require a corresponding methodology for policy's design. Further research must also address the related planning issues and outline the right framework to take advantage of the dynamic forces of TOD in urban areas. Consequently, research must strive to support integrated, policy-oriented urban and transport planning in which participatory planning practices give equal consideration to the interests of developers, stakeholders, and the general public.

\section{References}

Bae, C.-H. C., M.-J. Jun, and H. Park. 2003. The impact of Seoul's Subway Line 5 on residential property values. Transport Policy, 10(2):85 - 94. doi: 10.1016/S0967-070X(02)00048-3.

Bichsel, R. 1999. A silver rule for financing local transport facilities. Report, Département d'Econométrie et d'Economie Politique, Université de Lausanne, Switzerland. 
Brunn, S. and J. Williams. 1983. Cities of the World - World Regional Urban Development. New York: Harper \& Row.

Cervero, R. 1984. Journal Report: Light Rail Transit and Urban Development. Journal of the American Planning Association, 50(2):133-147.

Cervero, R. and J. Landis. 1997. Twenty years of the Bay Area Rapid Transit system: Land use and development impacts. Transportation Research Part A, 31(4):309 - 333. doi: 10.1016/S0965-8564(96)00027-4.

Cervero, R. and K.-L. Wu. 1998. Sub-centring and commuting: Evidence from the San Francisco Bay area, 1980-90. Urban Studies, 35(7):1059-1076.

Dabinett, G., T. Gore, R. Haywood, and P. Lawless. 1999. Transport investment and regeneration. Sheffield: 1992-1997. Transport Policy, 6(2):123 - 134. doi: 10.1016/S0967070X(99)00013-X.

Debrezion, G., E. Pels, and P. Rietveld. 2007. The impact of railway stations on residential and commercial property value: A meta-analysis. The Journal of Real Estate Finance and Economics, 35(2):161-180. doi: 10.1007/s11146-007-9032-z.

Dong, X., M. E. Ben-Akiva, J. L. Bowman, and J. L. Walker. 2006. Moving from trip-based to activity-based measures of accessibility. Transportation Research Part A, 40(2):163-180. doi: 10.1016/j.tra.2005.05.002.

Du, H. and C. Mulley. 2007. Transport accessibility and land value: A case study of Tyne and Wear. RICS Research Paper Series Volume 7 Number 3, Royal Institute of Chartered Surveyors.

Emerson, D. 1990. Framework for analyzing the impact of fixed-guideway transit projects on land use and urban development. Transportation Research Record, 1274:150-155.

Fotheringham, A. 1982. Distance-decay parameters: a reply. Annals of the Association of American Geographers, 72(4):551-553.

Fouracre, P. R., R. J. Allport, and J. M. Thomson. 1990. The performance and impact of rail mass transit in developing countries. Research report 278, Transport and Road Research Laboratory - Overseas Development Administration (TTR-ODA), London.

Gakenheimer, R. 1999. Urban mobility in the developing world. Transportation Research Part $A, 33(7-8): 671-689$. doi: 10.1016/S0965-8564(99)00005-1.

Gardner, G., J. Rutter, and F. Kuhn. 1990. The performance and potential of light rail transit in developing countries. Technical report, Transport and Road Research Laboratory - Overseas Development Administration (TTR-ODA), London.

Geurs, K. and J. Ritsema. 2001. Accessibility measures: Reviews and applications. Technical report, National Institute of Public Health and the Environment, Bilthoven, The Netherlands.

Geurs, K. T. and B. van Wee. 2004. Accessibility evaluation of land-use and transport strategies: Review and research directions. Journal of Transport Geography, 12(2):127-140. doi: 10.1016/j.jtrangeo.2003.10.005.

Giuliano, G. 1995. Land use impacts of transportation investments: Highway and transit. In S. Hanson, ed., The Geography of Urban Transportation, pp. 305-341. New York and London: The Guilford Press.

Greeneberg, K. 1988. Transit and changing urban character: The evolution of an intersection in Toronto. In J. Dodgson and N. Topham, eds., Bus deregulation and privatisation: An international perspective, pp. 47-54. Austin: University of Texas Press. 
Gutierrez, J., A. Monzón, and J. Piñero. 1998. Accessibility, network efficiency and transport infrastructure planning. Environmental and Planning A, pp. 1337-50.

Hall, P. and C. Hass-Klau. 1985. Can Rail Save the City? The Impacts of Rail Rapid Transit and Pedestrianisation on British and German Cities. Aldershot, UK: Gower.

Hall, P. and S. Marshall. 2002. The government's 10 year transport plan - land use implications. Technical report, Independent Transport Commission, Southampton, UK.

Japan International Cooperation Agency. 1999. Metro Manila urban transportation integration study. Unpublished.

Knight, R. 1980. The impact of rail transit on land use: Evidence and a change of perspective. Transport, 9(1):3-16.

Landis, J., S. Guathakurta, and M. Zhang. 1994. Capitalization of transportation investments into single-family home prices. Working Paper 619, Institute of Urban and Regional Development, University of California, Berkeley.

Lefaver, S. 1997. Private land with public partnerships for transit based development. Report 97-1, The Mineta Transportation Institute.

Magno-Ballesteros, M. 2000. The Urban Land and Real Estate Market in Metro Manila: A Socio-Economic Analysis. Ph.D. thesis, Katholieke Universiteit Nijmegen, The Netherlands.

McGee, T. 1967. The Southeast Asian City. New York: Praeger.

Morris, J. M., P. L. Dumble, and M. R. Wigan. 1979. Accessibility indicators for transport planning. Transportation Research Part A: General, 13(2):91-109. doi: 10.1016/01912607(79)90012-8.

Pill, J. 1988. Toronto: Thirty years of transit development. In W. Attoe, ed., Transit, Land Use and Urban Form, pp. 57-62. Austin: University of Texas Press.

Pushkarev, B., J. Zupan, and R. Cumella. 1982. Urban Rail in America. Bloomington: Indiana University Press.

RICS Policy Unit. 2002. Land value and public transport. Technical report, Office of the Deputy Prime Minister, London.

Rietveld, P. and P. Nijkamp. 2000. Transport infrastructure and regional development. In J. Polak and A. Heertie, eds., Analytical Transport Economics: An International Perspective, pp. 208-232. Cheltenham, UK: Edward Elgar.

Simpson, B. 1990. Urban rail transit: Costs and funding. Report, Transport and Road Research Laboratory, Crowthorne, UK.

Transit Cooperative Research Program. 2002. Transit-oriented development and joint development in the United States: A literature review. Research Results Digest, 52.

Walmsley, D. and K. Perret. 1992. The effects of rapid transit on public transport and urban development. Technical report, HMSO, London.

Wegener, M. and F. Fürst. 1999. Land-use transport interaction: State of the art. Technical report, Institut für Raumplanung Fakultät Raumplanung, Universität Dortmund, Germany.

Wright, L. and W. Hook. 2007. Bus Rapid Transit-Planning Guide. New York: Institute for Transportation and Development Policy, 3rd edition. 